San Jose State University

SJSU ScholarWorks

Doctoral Projects

Master's Theses and Graduate Research

Spring 5-2017

\title{
End of Life Care Practices for Patients Who Die in Intensive Care Units (ICU)
}

Jila Ghabeljoo

California State University, Northern California Consortium Doctor of Nursing Practice

Follow this and additional works at: https://scholarworks.sjsu.edu/etd_doctoral

Part of the Critical Care Nursing Commons

\section{Recommended Citation}

Ghabeljoo, Jila, "End of Life Care Practices for Patients Who Die in Intensive Care Units (ICU)" (2017).

Doctoral Projects. 66.

DOI: https://doi.org/10.31979/etd.7qmv-6aum

https://scholarworks.sjsu.edu/etd_doctoral/66

This Doctoral Project is brought to you for free and open access by the Master's Theses and Graduate Research at SJSU ScholarWorks. It has been accepted for inclusion in Doctoral Projects by an authorized administrator of SJSU ScholarWorks. For more information, please contact scholarworks@sjsu.edu. 


\section{ABSTRACT \\ END-OF-LIFE CARE PRACTICES FOR PATIENTS WHO DIE IN INTENSIVE CARE UNITS (ICU)}

Today, one in five hospital deaths happens in the intensive care unit with the expectation of twice as many by 2030 . Increasing, mortality has triggered a growing attention to end-of-life (EOL) care in the ICU. However, the lack of coveted EOL and palliative care skills creates a challenge for ICU nurses. The aim of this study was to assess the current practices of EOL care in the ICU. In this quantitative research, a retrospective chart review method was employed to analyze the collected data from a population 60 EOL patients who died in the ICU of a Southern California hospital. The results highlight the inadequate treatment of EOL discomforts. No patients received palliative care or POLST designation, and only one patient received hospice care. Also, the highest mortality happened within the first 6 days of the hospital stay, indicating the time sensitive nature of ICU admissions. Therefore, early planning of the comfort care for end-of-life patient and better communication with the inter-professional team is recommended.

Jila Ghabeljoo

May 2017 



\title{
END OF LIFE CARE PRACTICES FOR PATIENTS WHO DIE IN INTENSIVE CARE UNITS (ICU)
}

\author{
by \\ Jila Ghabeljoo
}

\author{
A project \\ submitted in partial \\ fulfillment of the requirements for the degree of \\ Doctor of Nursing Practice \\ California State University, Northern Consortium \\ Doctor of Nursing Practice
}

May 2017 


\section{APPROVED \\ For the California State University, Northern Consortium \\ Doctor of Nursing Practice:}

We, the undersigned, certify that the project of the following student meets the required standards of scholarship, format, and style of the university and the student's graduate degree program for the awarding of the master's degree.

Jila Ghabeljoo

Project Author

T. Katsma

Diane Katsma (Chair) Nursing

$\frac{\text { Fobet C. Machead no Pulliatiu medicine }}{\text { Committee member's name }}$

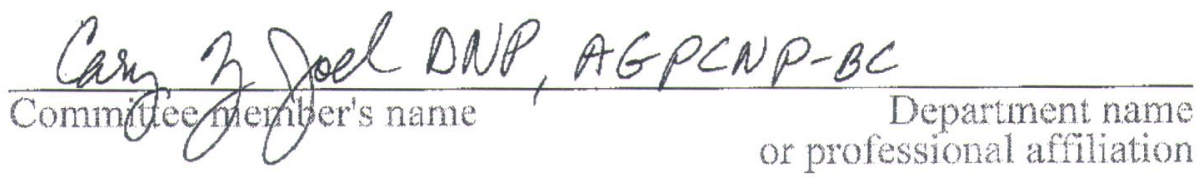




\section{AUTHORIZATION FOR REPRODUCTION OF DOCTORAL PROJECT}

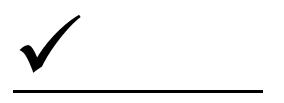

I grant permission for the reproduction of this project in part or in its entirety without further authorization from me, on the condition that the person or agency requesting reproduction absorbs the cost and provides proper acknowledgment of authorship.

Permission to reproduce this project in part or in its entirety must be obtained from me.

Signature of project author:

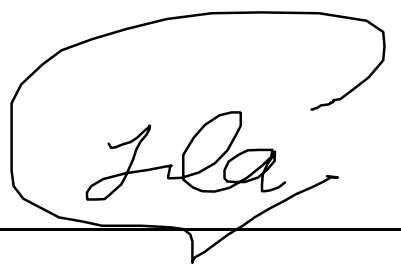




\section{ACKNOWLEDGMENTS}

This research is dedicated to my loving family for their unconditional love and support: to my oldest son, Younes, who is a gift from heaven, to the memory of my youngest son, Edris, whose spirit lifts me every minute, and to my devoted husband, Ali, who gave me the courage to continue my studies. I must thank my parents, Bahman and Maliheh, whose spiritual beliefs consistently pushed me to reach higher in life.

My thanks and appreciation go to all nurses, especially my peers in intensive care units; their dedication to the profession of nursing motivated me every day to assist with improving patient care. Most of all, my thanks go to my patients who give me encouragement to survive hurdles of life and humble me with their heroic stories. I am obliged for the support of the faculty and my thesis committee member who generously dedicated their time and experience, especially Dr. Cary Z. Joel for her encouragement, Dr. Sylvia Miller for her trust and vision, and Dr. Diane Katsma for her insightful guidance.

To God be the glory.... Great things He has done, and for greater things yet to come. 


\section{TABLE OF CONTENTS}

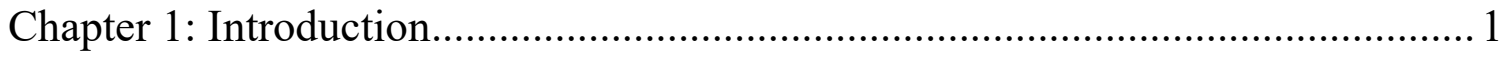

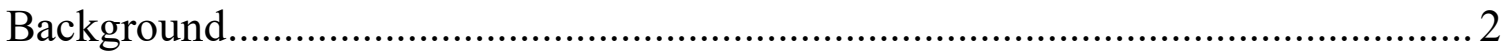

Significance of the Problem ................................................................................ 2

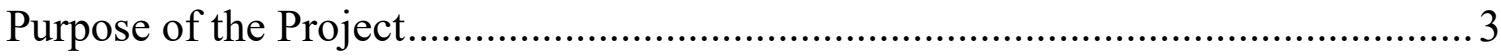

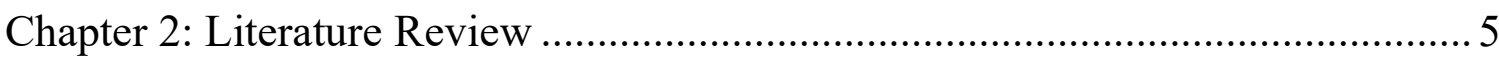

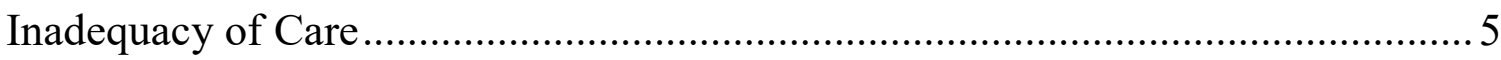

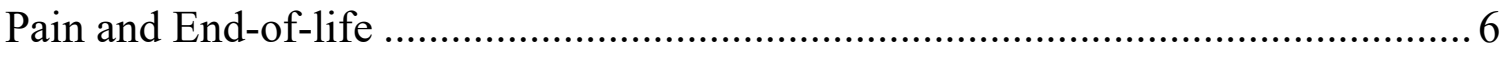

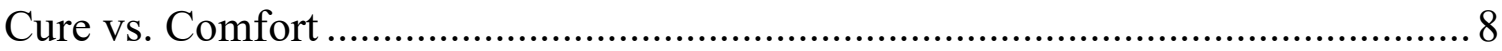

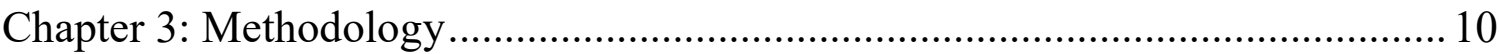

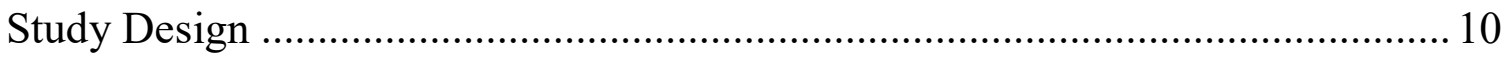

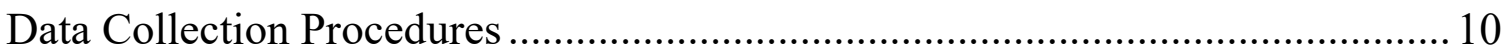

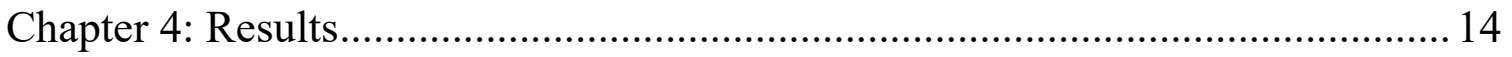

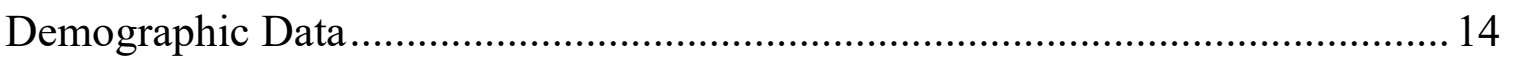

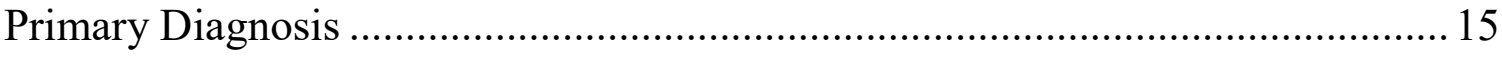

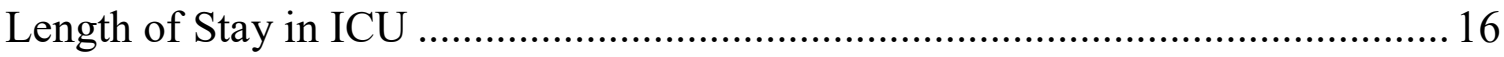

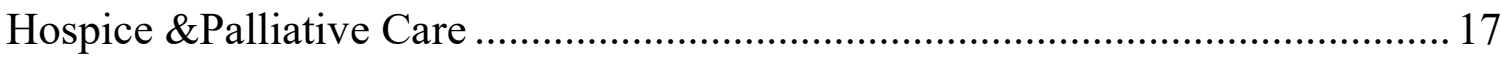

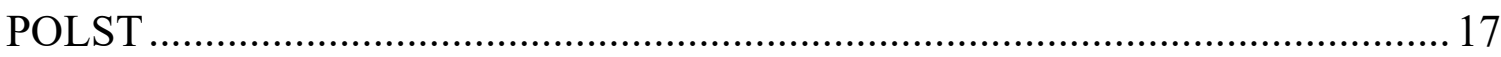

Time, Type and Quantity of Pain Medication ........................................................ 17

Nursing Flow Sheet Pain Management Documentation ........................................ 21

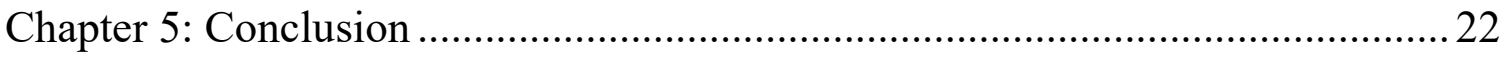

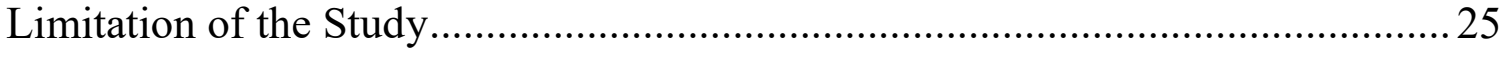

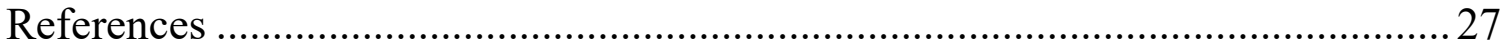


LIST OF TABLES ........................................................................... vii

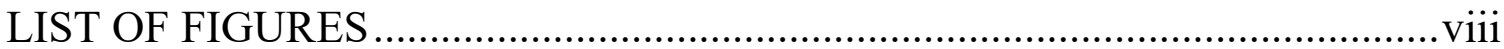




\section{LIST OF TABLES}

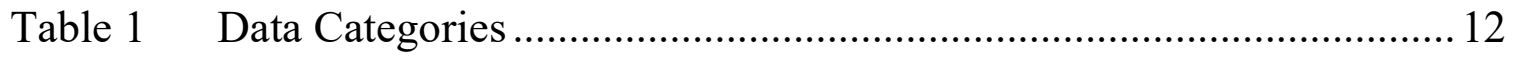

Table 2 Summary of Gender and Ethnicity ........................................... 14

Table 3 Patients' age statistics ................................................................. 14

Table 4 ANOVA test of primary diagnosis vs. ethnicity ............................. 15

Table 5 Classification of primary diagnosis by organ and body system. ........ 15

Table 6 Pain medication statistics .................................................... 17 


\section{LIST OF FIGURES}

Figure 1 Length of stay in ICU before death................................................ 16

Figure 2 Distribution of pain medication in the population ............................. 18

Figure 3 Distribution of medications among the end-of-life patients .............. 19

Figure 4 Dosage (a) Fentanyl, (b) Morphine, (c) Ativan, (d) Versed.............. 20 


\section{Chapter 1: Introduction}

In the United States, one out of five hospital deaths occurred in the intensive care unit (ICU), and it is predicted that by 2030 , the rate of elders dying in the ICU will double (Curtis et al, 2012). As more patients spend their last days in ICUs, it is important that ICU nurses provide appropriate end-of-life (EOL) care. It is more than half a century since ICUs were created to take on the arduous task of treating seriously ill patients. Since most of the time complications have ended in patient death, health journals started addressing ICU issues in a special part called the "Problem Page" (Fridth, 2014). Earlier articles have complained about ICU design in regards to the lack of privacy for dying patients. Patient death has been disputed as a preventable failure, inducing a feeling of guilt for the clinical staff. As the ICU became an integrated part of hospitals, the ICU specialty journals began publishing advances in end-of-life care. ICUs gradually converted into specialized units having skillful nurses at the core of the organizations. The ICU nurses became accustomed to patient deaths as a grave reality in spite of aggressive medical intervention treatment to save life as a part of the death-denying culture (Nelson, 2006). Intensive care nursing has been confronted with fundamental questions about the meaning of pain and death (Hov et al., 2007). ICUs have become the ultimate places of endeavor to save lives. However, ICU nurses are trained to save lives; therefore, even if some nurses are willing to provide end-of-life care, they generally lack basic palliative care skills, which are in growing demand today (Costello, 2006). 


\section{Background}

Ethical dilemmas, cultural differences, and preference practices can easily arise in the ICU during the end of life. Having the sensitive theory of caring as a framework and systemic re-evaluation will assist the administration in addressing concerns of staff and family members while preventing a dehumanizing act of care in the robotic atmosphere of the ICU. As Florence Nightingale, the mother of modern nursing, believed through environmental alteration, one can put the patient in the best possible condition for nature to act (Selanders, 2010).

Taking care of the end of life patients is a specialty beyond the expertise of clinical practice staff and ICU nurses. It requires a high level of interaction with another human being. The development of such caring relationships between a nurse and dying patient is defined by Jean Watson. According to Watson's theory, in an effective caring environment, the behavior of nurses towards terminally ill patients should fulfill the following requirements: (i) assist in the end-of-life comfort process, (ii) treat persons as whole, (iii) develop authentic relationships, and (iv) assist in humanity development (Watson, 2008). The nurse-patient relationship becomes transpersonal and authentic when the nurse embraces the spirit of the patient and provides holistic care (Watson, 1999). In this study to improve the quality of end-of-life care, ICU nurses should behave according to the principles of Watson theory.

\section{Significance of the Problem}

The process of dying in a critical care unit is complicated, and the extent of literature on the obstacles that hamper the provision of care and pain medication at the end-of-life stage is inadequate (Beckstrand, 2017). Today, it is well accepted that in some 
situations, conventional curative medical care should be gradually replaced by end-of-life care. However, according to many ICU healthcare professionals, such a transition is the most problematic stage in providing end-of-life care (Coombs, et al., 2016). The common problems with the ICU are (i) ineffective pain management, (ii) lack of contribution from ICU nurses in the care planning and decision making for the end-of-life patients, and (iii) an unfit atmosphere for end-of-life care (Espinosa et al., 2010). These difficulties may be alleviated by hospice programs that respond the patient needs in such circumstances (Bailey et al, 2012).

In summary, the EOL care problem is still new in clinical care study. Not enough research is found about EOL issues in the past decade. There is a gap of knowledge regarding improving existing care for EOL patients and implementing the non-curative alternatives such as palliative and hospice cares. This study is intended to address this gap in knowledge by suggesting future improvements of the existing end-of-life care practice.

\section{Purpose of the Project}

The purpose of this study was to examine the end-of-life care practices for patients who died in the ICU. Specifically, the study has addressed the assessment of pain by nurses, pain medications, including doses given, the frequency of pain assessment, pain management strategies, the length of stay prior to death, hospice and palliative care status, and the existence of physician orders for life-sustaining treatment (POLST). A first step to understanding the process of care for patients at end of life is identifying current practices. The purpose of this study is to assess end-of-life care practices for patients who die in intensive care units. 
In this study, the following retrospective data has been collected from both electronic and paper records to identify the type of care and pain management for sixty patients:

- Acquire demographic data of deceased patients in the ICU with comfort care order.

- Identify length of stay in ICU before death.

- Identify hospice care status versus non-hospice care.

- Identify palliative consult versus non-palliative consult.

- Identify the time frame of palliative consult between the admission and death.

- Determine the existence of (POLST) at the time of admission.

- Identify the time, type, and quantity of pain medication.

- Describe nursing pain management documentation.

Understanding the practices of the end of life care in the ICU is an important first step in the process of improving the care of patients dying in the ICU. 


\section{Chapter 2: Literature Review}

A literature search was conducted in both PubMed and CINAHL electronic databases for the past decade. The keywords "ICU" and "end-of-life care" were paired using the Boolean connector "AND" with each of the following keywords: "comfort care," "pain," "death," "ICU nurse," OR "hospice” and "palliative." Articles were limited to those published in the English language and studies concerning adult subjects in a hospital or institutional setting, designed to understand the quality of care for end-oflife in the ICU.

\section{Inadequacy of Care}

Death in the ICU is logically the starting point of the literature review for this study, which is centered on the end-of-life agenda. According to data collected by the National Center for Health Statistics (NCHS), in 2010, a total of 2.5 million deaths occurred in the United States. One-third (33\%) of the total deaths happened in hospitals (Hall et al, 2013). On the other hand, $10 \%$ to $29 \%$ of the hospital fatality were adult ICU patients (SCCM.org, 2017). A survey of 2,000 critical care nurses using quantitative/ qualitative mixed methods revealed that existing care for the end-of-life patients is still inadequate (Beckstrand, 2017). The article compared the most common obstacles in EOL for 17 years since 1998. In essence, some problems were alleviated while others became worse. Among the increased problems was the insufficiency of nursing time assigned to the EOL care, as staff has been increasingly consumed with life-saving measures. The study recommended better evaluation of the family health literacy about EOL. Other recommendations were earlier detection of EOL patients, improving multidisciplinary 
communication, and ensuring the patient wishes. ICU nurses are focused on saving lives rather than end-of-life measures.

A literature review by Efstathiou and Clifford (2011) using meta-analysis confirmed the inadequacy of end-of-life care as well. The purpose of the article was to investigate the challenges for critical care nurses regarding end-of-life care. According to this research, the short phase of a patient's dying posed a great challenge for the ICU nurses. Consequently, the end-of-life care in the ICU occurred early in the admission. The article recommended evaluation of existing EOL practices and emphasis on skill development for EOL care to improve the knowledge of critical care nurses.

\section{Pain and End-of-life}

Pain management is a crucial part of medical care for critically ill patients. The ICU is an exclusive care setting where patients receive swift and aggressive life-sustaining interventions, but pain and anguish are common. Despite the importance of pain management, only a handful of research analyses were concentrated on the study of pain for end-of-life care (Mularski et al, 2009). A trans-disciplinary review by Mularski et al. focused on pain assessment and management within the comprehensive scope of palliative care. The article emphasized the importance of pain management for curative or supportive care in the ICU. According to this research, to achieve excellent pain management, in addition to monitoring and evaluating the pain, knowledge, and skill in pharmacologic, behavioral, social, and communication strategies were needed. In addition, Mularski et al investigated a variety of pain medications during withdrawal of life-sustaining therapies in the ICU. The following guidelines have been suggested to achieve comfort during end-of-life care: 
- A suitable dosage of opiates and benzodiazepines depending on the patient status.

- ICU nurses should educate the patients' family by communicating with them and providing necessary information about the withdrawal process.

In addition, most of the ICU nurses in the study believed that the development of checklists and objective scoring systems had improved end-of-life care in their unit.

In a prospectively analyzed study, Bailey et al. (2012) discussed baseline pain management practices for dying patients in six veteran administration medical centers (VAMCs). Relevant factors were examined including pain medication orders in the last 7 days, 48 hours, 24 hours, and the time of death. According to the World Health Organization (WHO), pain has been recognized as a major health problem and should be handled properly. WHO (1996) has provided a guideline for pain assessment and treatment. The organization also selected opioids, which can be administered in gradual increments until the right dose is found, as the medication of choice for pain management. But according to Bailey et al, despite opioids' effectiveness as a pain reliever, inadequate treatment of pain at the end of life remains an important public health issue. The study demonstrated that opioids were not effectively used in hospitals and nursing homes where the patients spent the last days of their lives. The article recommended: (i) improving the usage of opioids, (ii) enhancing the family involvement, and (iii) discussing on end-of-life care. Improving recognition of the dying process and proactive planning for pain control has also been suggested. 


\section{Cure vs. Comfort}

Aggressive treatment blended with advanced technology with the intention of healing and survival is the goal of critical care units. However, the gravity of patient illnesses potentially makes the ICU the highest mortality department in the hospital. That is why the ICU is distinguished with dual care service: curative care and palliative care. Upon the patient's arrival, curative care is performed with aggressive treatment using all the advanced technology available at its disposal. Once the patient becomes terminally ill, the focus may change to palliative care. Consequently, ICU nurses should be capable of switching their role from a conventional nurse to a palliative caregiver as well (Jukic et al., 2016).

For the past twenty years, the skill of palliative care has evolved rapidly into a mainstream science to help end-of-life patients. A retrospective study using chart review has investigated the potential occurrence of futility treatment in the ICU. The research on the 429 deceased ICU patients underscored the futility of long ICU treatment compared to palliative care (Jukic et al., 2016). Analysis of the deceased patients' charts found that at least $23 \%$ of the deceased population had potential futile treatment. As a result, some of the patients did not need prolonged ICU treatment and would have been better treated through palliative care. The article suggests that to avoid medically futile treatment in ICUs, palliative care unit needs to be established. Implementation of protocols and ethical committees are suggested to improve decision making regarding which patients will be transferred to palliative care. The importance of palliative care programs for the end-oflife care has been emphasized. 
In a cross-sectional descriptive study using a Likert scale questionnaire, 277 RNs from 29 ICUs in the Czech Republic participated. Part of the study assessed the RNs practice with respect to end-of-life care. The research highlights the importance of RNs understanding and participation in palliative care (Kisvetrova, 2015). The same study emphasizes the value of the palliative care for the ICU end-of-life patients.

From the above literature reviews, there is an evident gap of knowledge about endof-life care in ICUs. More research is needed to understand what is currently happening to patients who die in the ICU. In this study, the current practice of EOL care was analyzed from the patients' clinical data. The purpose was to understand the shortcomings and discover the key factors to a successful practice by closing this knowledge gap. 


\section{Chapter 3: Methodology}

\section{Study Design}

This investigation has been categorized as a quantitative research descriptive design. A retrospective chart review (RCR), which is also called medical record review (MRR), has been utilized as a technique to exploit previously collected data as the basic source of information for the research study. MRR can be an ideal method for investigating the existing or pre-collected data on events that have already happened. As an advantage, retrospective chart review may be used as the initial study-generating hypothesis to be researched further by a larger, more expensive prospective investigation.

A disadvantage of the medical record review could be the data must be valid and reproducible to be considered for research (Worster, 2004). To ensure the validity, the data collection has been streamlined in clearly defined categories as will be given by Table 1. This study is unique as it has been focused on a deceased population, where the questions about their end-of-life care cannot be answered by a medical trial or randomized study. That can be considered as a rationale behind using MRR in the current research.

\section{Data Collection Procedures}

The setting for the data collection was a 194-bed hospital located in a northern suburb of San Diego. The hospital has grown into a busy, full-service medical facility that cares for more than 80,000 patients a year in North County. The hospital's ICU, though comprising only 12 beds, has a fast turnaround time in order to accommodate the growing patient population. That may justify the high rate of deceased ICU patients. 
In order to reduce the time and cost of data collection, a purposeful sampling has been used. In this project, the population has been defined as a group of 425 patients who died in the ICU between 2012 and 2016. The list of deceased patients was searched in descending order, beginning with the latest data. The goal was selecting the individuals who were 18 years and older and had end-of-life care orders in their records. Overall 60 cases that met the above criteria were chosen. It is well known that selecting a subgroup of individuals within a statistical population may suffice to assess the characteristics of the whole population.

Data for this project has been collected through review of patient medical records using the eDOCS electronic database. This program provides scanned documents such as physician notes, physician orders, nurses' notes, radiology reports, discharge paperwork, and death reports. An additional database called Centricity EMR was accessed for laboratory results, medication records, dictations, and additional nursing notes. Centricity Electronic Medical Record (EMR) offers the medical staff an ambulatory medical record system that can integrate with finance and management practice. The system provides valuable online patient records to the physicians and nurses in a fast and efficient manner. Centricity is designed to enhance the clinical productivity of the ambulatory practice. Centricity EMR allows collaboration between the staff by enabling data sharing with existing clinical or financial systems, anytime and anywhere (GE Healthcare, 2017). The data collection was conducted on the selective items that were relevant to the end-of-life care, including demographic data.

No patient identifiable data left the hospital or was stored electronically. Data on variables of interest were extracted from the medical record and typed by the principal 
investigator into a data collection tool created in Excel. The data set from each patient was given an identification number not related to their medical record to preserve health information and patient privacy. For ethical consideration, the researcher obtained approval from the institutional review board (IRB).

Although the number of samples in this study was limited to 60 , each sample data was diversified into a handful of categories providing significant information. However, the redundancy of information created an ambiguity for some of the categories. For example, the patient's diagnosis was recorded differently in the emergency room admission, ICU admission, physicians' progress note, dictation of events, nurses' notes, consultation multi-disciplinary progress note, and coding summary primary diagnosis.

For research clarity, the data categories and the data sources are shown in Table 1.

Table 1 Data Categories

\begin{tabular}{|l|l|}
\hline Category & Source \\
\hline $\begin{array}{l}\text { Demographic data of deceased patients in the ICU } \\
\text { under comfort care (gender, age at death, and } \\
\text { ethnicity) }\end{array}$ & $\begin{array}{l}\text { Face sheet form, nursing admission, and } \\
\text { physician dictation }\end{array}$ \\
\hline Primary diagnosis & Coding summary primary diagnosis \\
\hline Length of stay in ICU before death. & ICU admission physician order sheet \\
\hline Hospice care information (if any) & $\begin{array}{l}\text { Physician dictation, progress note, nursing } \\
\text { flow sheet, and physician order sheet }\end{array}$ \\
\hline $\begin{array}{l}\text { Palliative consult information from admission to } \\
\text { death (if any) }\end{array}$ & $\begin{array}{l}\text { Physician dictation, progress note, nursing } \\
\text { flow sheet, and physician order sheet }\end{array}$ \\
\hline $\begin{array}{l}\text { Written Physician Orders for Life-Sustaining } \\
\text { Treatment (POLST) information }\end{array}$ & POLST form \\
\hline Time, type, and quantity of pain medication & $\begin{array}{l}\text { Physician order post comfort care order } \\
\text { status change }\end{array}$ \\
\hline Individual pain management documentation (if any) & ICU nursing flow sheet \\
\hline
\end{tabular}

The collected data for each deceased patient was entered in a spreadsheet under the specific categories as given in Table 1. Two types of data were gathered, namely numerical (such as age, days of hospital stays) and categorical (such as gender, ethnicity, etc). The categorical data were converted to numerical entities or numbers in order to be 
analyzed by a computer program. The final spreadsheet showing a numerical table was read and analyzed by IBM SPSS 4.0 statistical software. The presentation of data was through tables containing the results in the form of numbers and statistics. 


\section{Chapter 4: Results}

In this chapter, the results of the statistical analysis on the research data are explained. As mentioned before, these retrospective data has been collected from the end of life patients who died in the ICU. The raw data was subsequently converted into the proper spreadsheet file (dataset) so that it could be directly imported by the IBM SPSS 24.0 Statistical Analysis Software. The resulting dataset includes both numerical and categorical information.

\section{Demographic Data}

The baseline characteristics of the patients in terms of gender and ethnicity are detailed in Table 2.

Table 2 Summary of Gender and Ethnicity

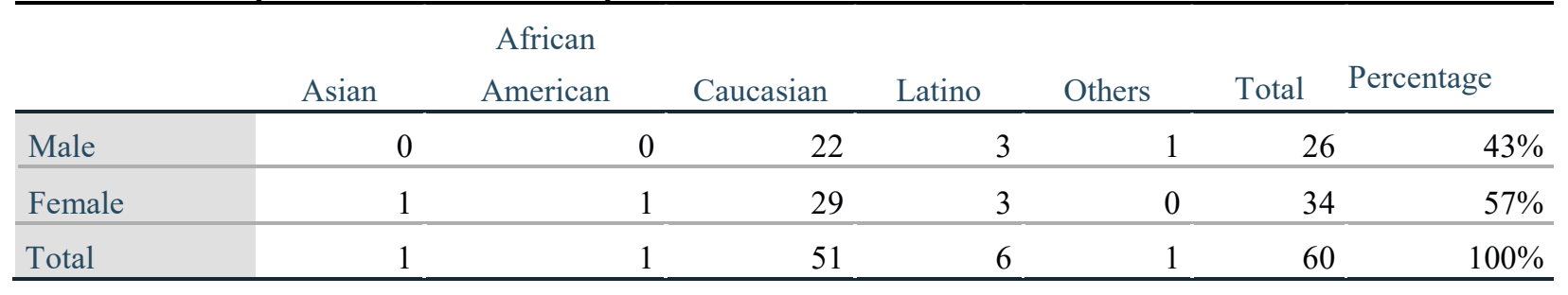

It is shown that out of 60 patients, $43 \%$ are male, and $57 \%$ are female. Also, the ethnicity profile is dominated by Caucasians, constituting $85 \%$ of the population. A descriptive analysis of the patients' age as summarized in Table 3 , shows a normal distribution, with an average age of 74 with the range of 37 to 96 years old.

Table 3 Patients' age statistics

\begin{tabular}{lrrrrrr} 
& & & & & \\
& N & & Minimum & Maximum & Mean & Std. Deviation \\
\hline Age & 60 & 37 & 96 & 74 & 13 \\
\hline
\end{tabular}


The result of the ANOVA regression test of the primary diagnosis versus the ethnicity is given at Table 4 . The significance coefficient is $.961>0.05$ and $\mathrm{F}<1$, indicating no significant relation between the primary diagnosis and the population ethnicity. This has been expected since $85 \%$ of the patients are Caucasian, leaving no room for other ethnic groups.

Table 4 ANOVA test of primary diagnosis vs. ethnicity

\begin{tabular}{lccccc}
\hline \multicolumn{5}{c}{ ANOVA $^{\mathbf{a}}$} & \\
Model & Sum of Squares & df & Mean Square & F & Sig. \\
\hline Regression & .017 & 1 & .017 & .002 & $.961^{\text {b }}$ \\
\hline Residual & 414.583 & 58 & 7.148 & & \\
\hline Total & 414.600 & 59 & & & \\
\hline
\end{tabular}

a. Dependent Variable: Primary diagnosis

b. Predictors: (Constant), Ethnicity

\section{Primary Diagnosis}

In order to find a clear picture from 60 different diagnoses, a summarized

classification is shown in Table 5, where the conditions have been grouped by organ and body system (University of Maryland, 2017).

Table 5 Classification of primary diagnosis by organ and body system.

\begin{tabular}{lcc}
\multicolumn{1}{c}{ Primary Disease } & No. of Patients & Percentage \\
\hline Brain/ Nervous System & 12 & $20 \%$ \\
\hline Infectious Disease & 12 & $20 \%$ \\
\hline Respiratory System & 11 & $18.3 \%$ \\
\hline Digestive System & 8 & $13.3 \%$ \\
\hline Heart/Vascular System & 7 & $11.7 \%$ \\
\hline Cancer & 5 & $8.3 \%$ \\
\hline Musculoskeletal System & 4 & $6.7 \%$ \\
\hline Endocrine System & 1 & $1.7 \%$ \\
\hline Total & 60 & $100.0 \%$ \\
\hline
\end{tabular}


Overall, brain related and infectious diseases counted for $40 \%$ of the mortality. Respiratory failure disease claimed another $18 \%$ of the lives. On the contrary, only $8 \%$ of the patients died from cancer as well as one individual who died from diabetic complications, which is grouped under the endocrine system.

\section{Length of Stay in ICU}

The length of stay in the ICU before death spanned from 1 day to 24 days. The average was derived from being 7 days with a standard error of $80 \%$. The graphical representation of the data is shown in Figure 1.

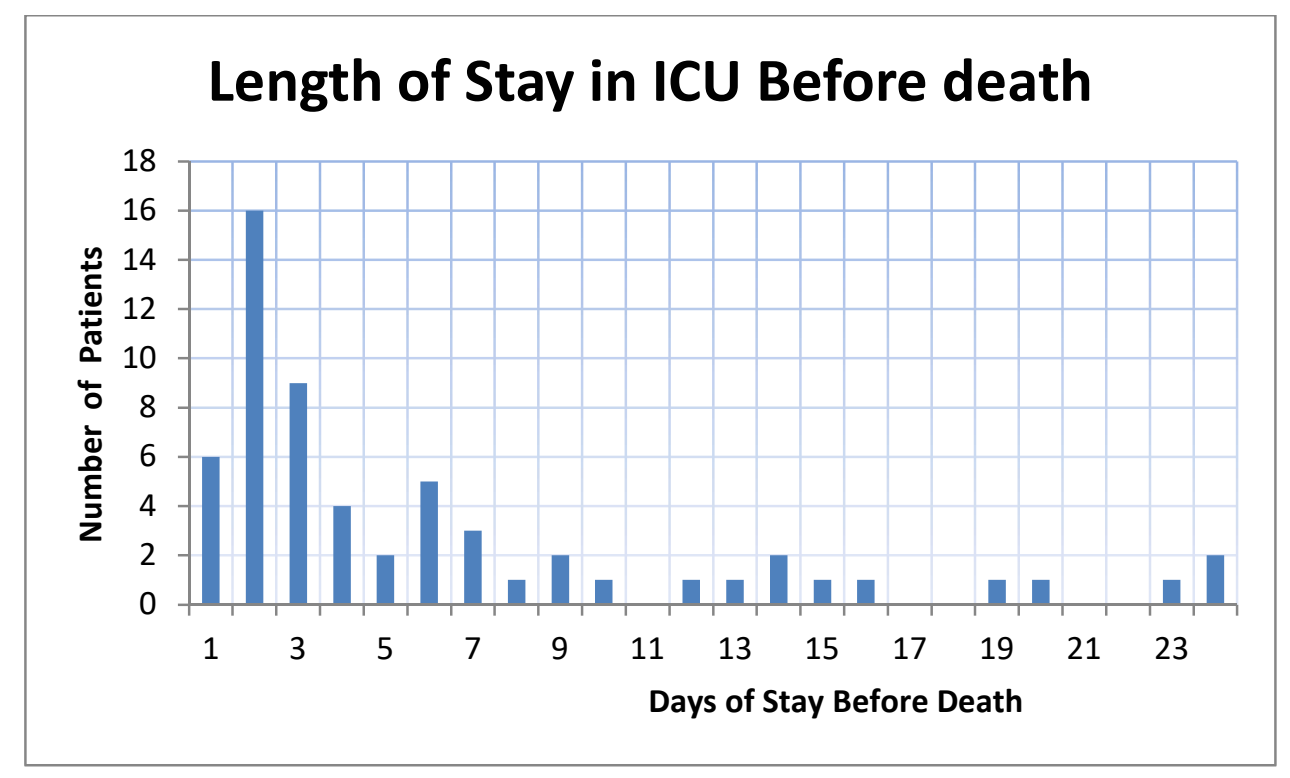

Figure 1 Length of stay in ICU before death

The most common length of stay was 2 days, which occurred for 16 end-of-life patients. 


\section{Hospice \&Palliative Care}

According to the data, only one patient benefited from hospice care. A 91-year-old male patient, who suffered from infection and inflammatory reaction when he was initially treated with an indwelling catheter, was put on 295 hours hospice care before death. Similarly, there were a few patients (only 15\%) who benefitted from palliative care ranging from 2 hours to 28 hours before death. The remaining (85\%) never had palliative care.

\section{POLST}

Physician orders for life-sustaining treatment (POLST) are important information on the clinical record of end-of-life ICU patients. Once the POLST is performed, it should be recorded in the database. In this research, there was no POLST information on the population data.

\section{Time, Type and Quantity of Pain Medication}

The statistical test of the pain medication profile applied to the deceased patient population is shown in Table 6. In $73 \%$ of the cases, the frequency of pain medication has been recorded as 1 to 2 hours. Also, in four cases, the pain medication was administered every 12 hours.

Table 6 Pain medication statistics

\begin{tabular}{lccc}
\hline & Hours & No. of Patients & Percentage \\
\hline Pain & 0 & 11 & 18.3 \\
\cline { 2 - 4 } medication & 1 & 21 & 35.0 \\
\cline { 2 - 4 } Frequency & 2 & 23 & 38.3 \\
\cline { 2 - 4 } [hour] & 4 & 1 & 1.7 \\
\cline { 2 - 4 } & 12 & 4 & 6.7 \\
\cline { 2 - 4 } & Total & 60 & 100.0 \\
\hline
\end{tabular}


The graphical analysis of the pain medication administration is also shown in

Figure 2. The histogram is shown with the ideal normal distribution in the background. The graphical comparison indicates the similarity of the pain medication profile to a lefttailed normal distribution with the average value of about 2 hours. Four individuals had pain medication every 12 hours.

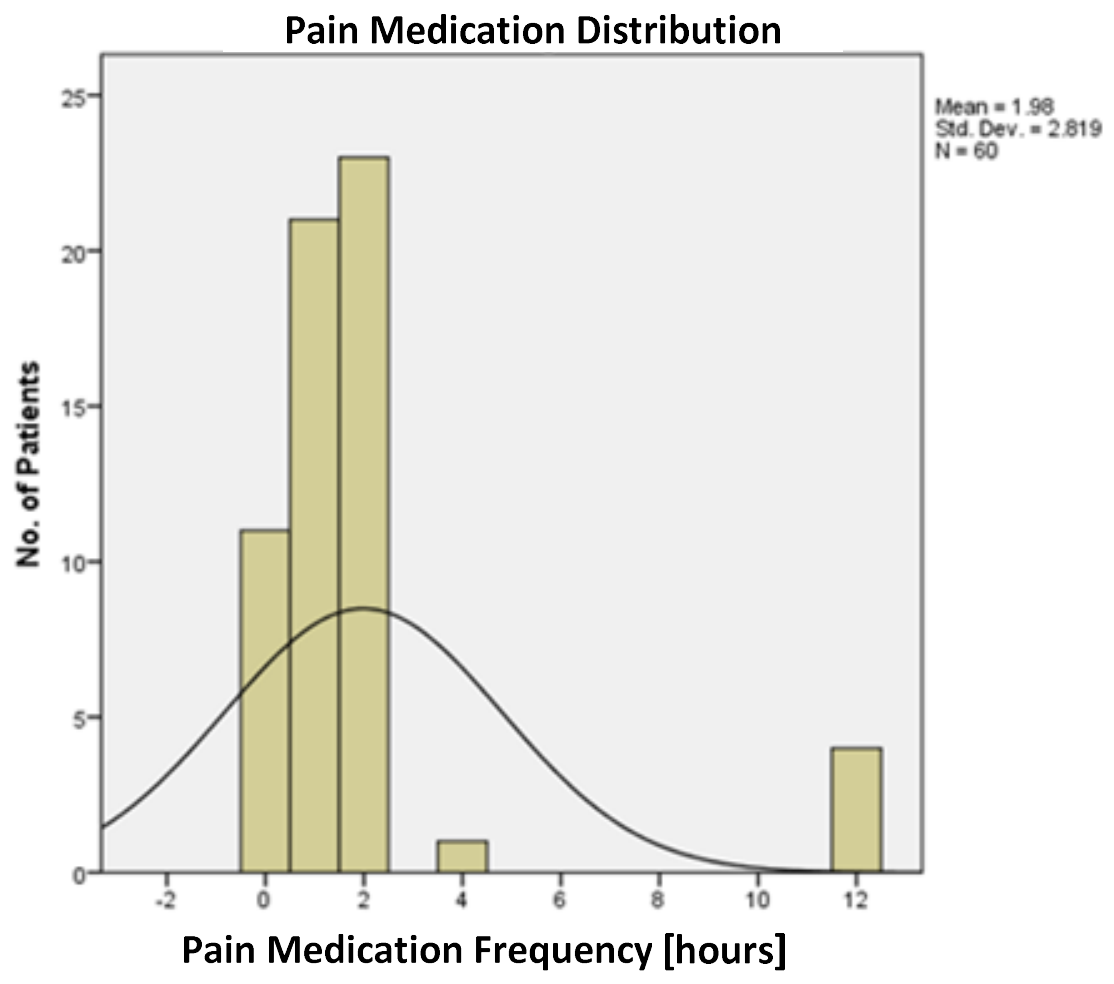

Figure 2 Distribution of pain medication in the population 
The patients were on one or two types of pain medications.

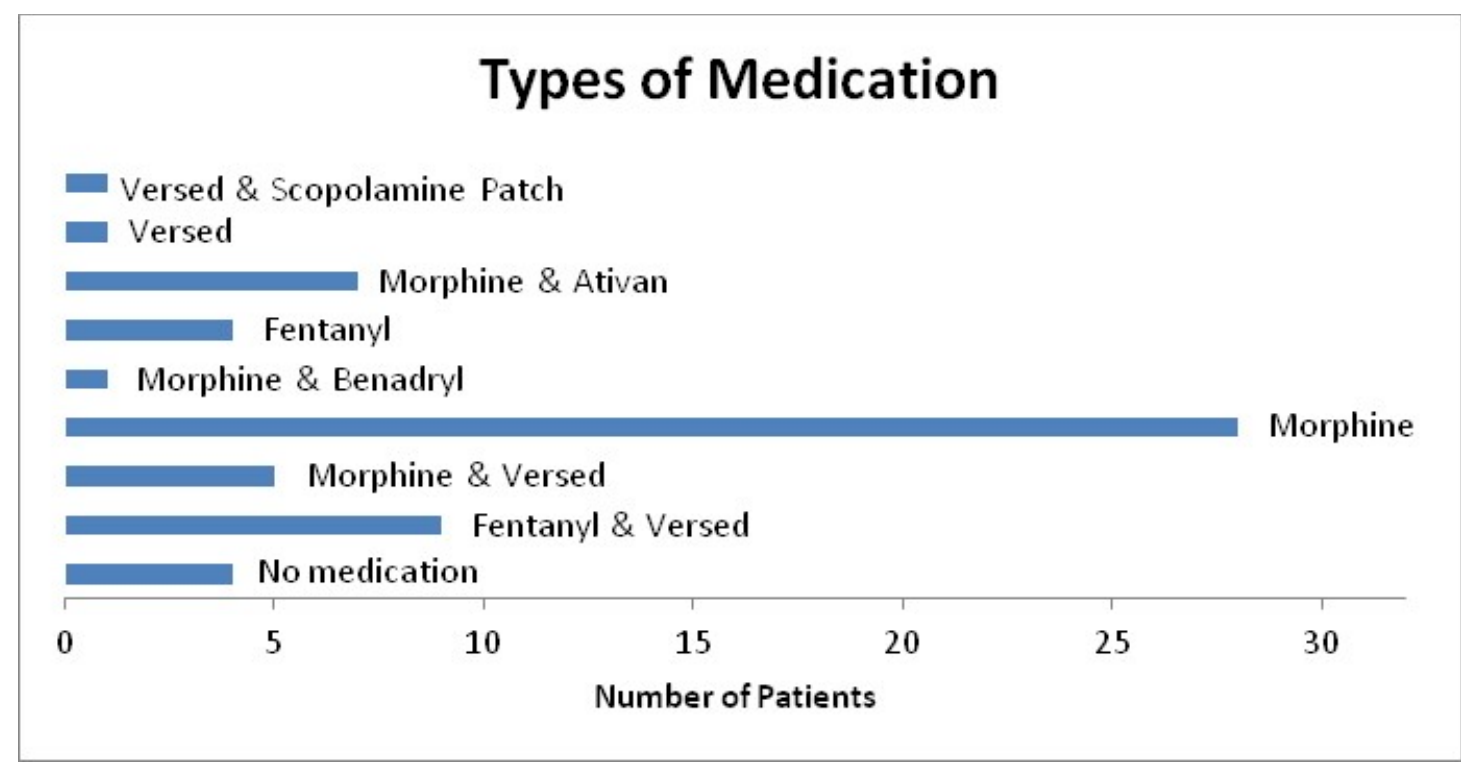

Figure 3 shows the distribution of various types of medication for the study population.

Four people never had pain medication before death. In addition, $46 \%$ were administered only Morphine. The second highest medication among $15 \%$ of the population was a combination of Fentanyl and Versed, followed by $11 \%$ with an administration of Morphine and Ativan. The other choices of medication fall below 1\% of patients.

\section{Types of Medication}

Versed \& Scopolamine Patch

Versed

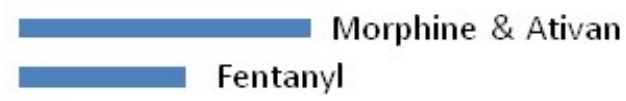

Morphine \& Benadryl

Morphine

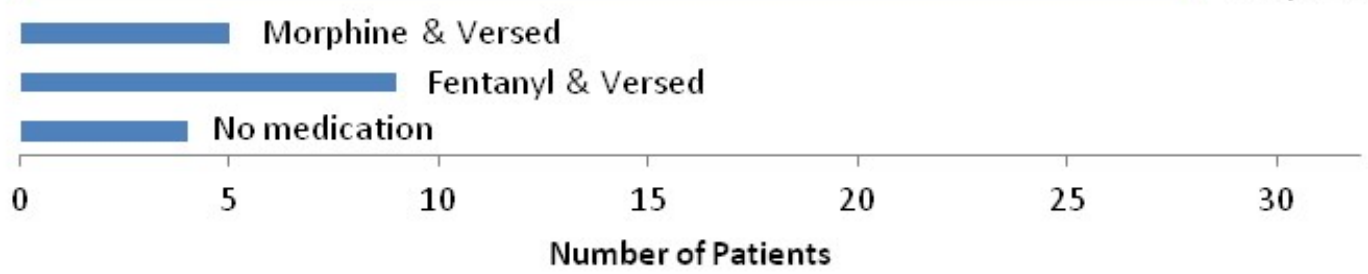

Figure 3 Distribution of medications among the end-of-life patients 
The dosage of prominent pain medicines administered for the population is shown in Figure 4. Fentanyl was prescribed at a minimum of 25 to a maximum of 300 micrograms per hour as shown in Figure 4-a. Morphine was the most commonly prescribed pain medicine among the population with a dosage range of 1 to 20 milligram per hour. The common dosage of $2 \mathrm{mg}$ /hour was administered to 12 patients as shown in Figure 4-b. The dosage range for Ativan was 1 to $5 \mathrm{mg}$ /hour (Figure 4-c), and Versed has been used in a wide range of dosages between 2 to $20 \mathrm{mg} / \mathrm{hour}$, with the common dosage being $2 \mathrm{mg}$ /hour per Figure 4-d. All combinations of medications were administered via intravenous (IV) route except for the Scopolamine patch. In one case, an IV push of 25 mg of Benadryl was administered as well as Morphine.

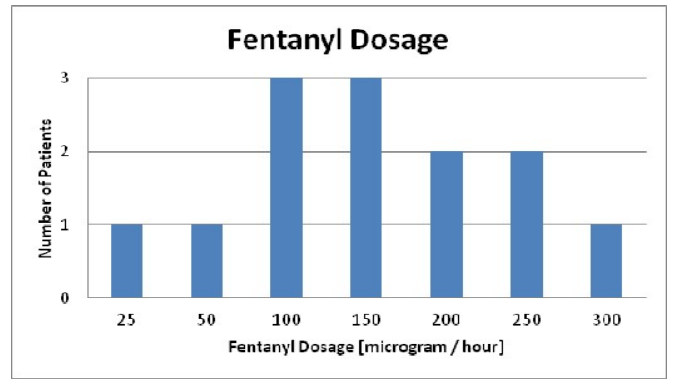

(a)

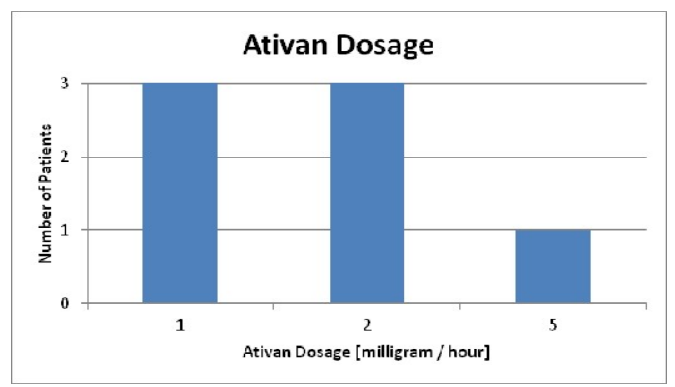

(c)

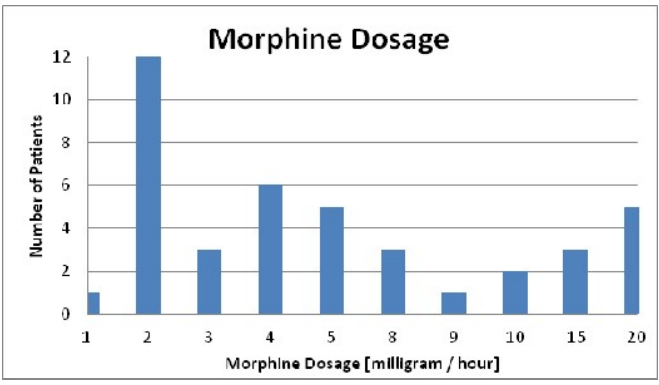

(b)

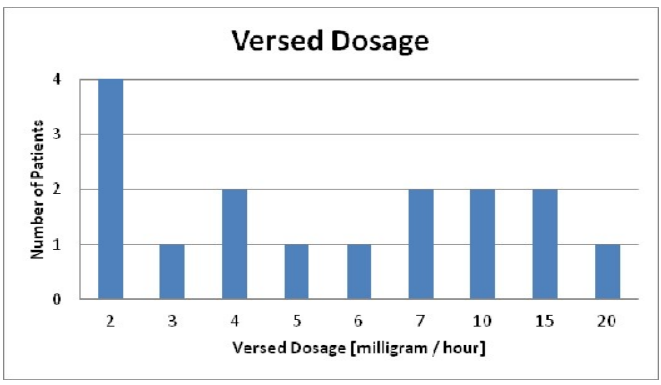

(d)

Figure 4 Dosage (a) Fentanyl, (b) Morphine, (c) Ativan, (d) Versed. 


\section{Nursing Flow Sheet Pain Management Documentation}

According to nursing flow sheet documentation, four different pain scales have been used. The most commonly used pain scale for assessment at end-of-life care patients was the Critical Care Pain Observation Tool (CPOT) with $70 \%$ of cases. Overall, $18 \%$ of cases lack any pain scale in their documentation. Documentation indicated a Numeric Rating Scale (NRS) was employed for $5 \%$ of the patients. About $2 \%$ of the cases were associated with the Checklist of Nonverbal Pain Indicators (CNPI) pain scale. For the last $5 \%$, Patient Conditions (PC) was used. 


\section{Chapter 5: Conclusion}

Healthcare providers should view death not only as a medical term but also a human approach. Differentiation between good and bad deaths corresponds directly to symptoms relief, respecting patients' wishes, and containing patients' self-images (Ternestedt et al, 2002). As a result, a dignified and respectful end of life care management in a modernized ICU is deemed necessary for the satisfaction of patients and their families. To achieve this goal, the issue of existing end-of-life care practice needs to be identified and avoided in the future. In this conclusion, the results obtained in Chapter 4 are discussed, and the obstacles of the current end-of-life care practices are identified as much as possible. Finally, recommendations for investigation are provided to alleviate the struggle of the existing end-of-life care practices.

One of the data categories is the primary diagnosis of the population consisting of 40 diseases. In this research, the brain related diseases had the highest mortality rate, $20 \%$, from 61 to 91 years old, whereas infectious diseases had the highest fatality, $20 \%$, from 45 to 91 years old. Respiratory diseases, $18 \%$, spread over the entire age range, starting with the youngest (37) to oldest (91). Nonetheless, in this population, the death rate due to heart diseases was modest at $11.7 \%$ compared to national statistics, in which heart disease is distinguished as the number one killer (Xu et al., 2016). The high rate of death due to infectious disease underscores the importance of early detection and treatment of sepsis. This research emphasizes the constant monitoring and treatment of sepsis based on tangible clinical data.

Another data category is the length of ICU stay before death, which has been explained in Chapter 4 (Figure 1). The bar graph shows a maximum number of deceased 
patients with 2 days of stay. Overall, the length of stay for $70 \%$ of the population was 6 days or less. This outcome has been compared with the results published from the BMC Medical Research Methodology (Brock et al, 2011), which has investigated the hospital mortality rate versus the length of stay.

From the interpretation of Brock's analysis, the probability of mortality is relatively high during the first 3 days $(p>0.7)$, and it gradually reduces with the increased length of stay. This interpretation is in agreement with the result of Chapter 4 (Figure 1), showing the highest mortality rate (70\%) during the first 6 days. Such a comparison is approximate, given the limited sample size of the population in this research. However, an important conclusion can be deducted: a high percentage of the end-of-life patients died within 6 days of their ICU admission. In other words, it shows the time sensitive nature of ICU admissions in order to identify comfort care for end-of-life patients versus aggressive care to treat and save lives.

According to the retrospective data for the palliative care as summarized in Chapter 4, there is a scant amount of information on palliative care practices on the population. The majority of patients ( $85 \%$ ) never had palliative care, and only one patient benefited from prolonged hospice care (295 hours) before death. Consequently, the majority of patients were deprived of hospice and palliative care. However, there is strong evidence in the literature enforcing the importance of palliative care for end-of-life patients (Abrahm, 2011). Also, there is no record of physician orders for life-sustaining treatment (POLST) among the patients. POLST has been suggested in the literature as a helpful tool for initiating end-of-life conversation and revealing patients' treatment preferences 
(Hickman, 2009). Future studies should include data related to hospice and palliative care to find out their impact on end-of-life patients.

Controlling pain is a key to the comfort of the dying patient. An acceptable level of pain and symptom management is necessary in order to avoid a prolonged dying period with anguish and suffering for end-of-life patients (Chochinov, 2006). The statistics in Table 5 in Chapter 4 shows $18 \%$ of the population never had pain medication. The comparison on the bar graph in Chapter 4 (Figure 2) with the left-tailed normal distribution indicates the 2-hour average as a realistic medication frequency for the population, whereas the 12-hour timing, which is located outside of the normal distribution, is an unrealistic medication frequency. Regarding the type of medication, Morphine was administered to about $70 \%$ of the population (Chapter 4, Figure 3). Overall, narcotics (opioids) were the medication of choice, including Morphine and Fentanyl, which were administered in $90 \%$ of cases. However, pain is not the only discomfort for the end-of-life patient. There are other difficulties such as nausea, agitation, shortness of breath, and delirium that should be treated with different types of medicines. According to Chapter 4 (Figure 4-d), a quarter of patients were prescribed Versed (Benzodiazepine) as a prophylactic treatment to reduce the risk of agitation and increase relaxation. However, with the exception of Scopolamine patches, no further medication was prescribed to treat other types of discomforts. In conclusion, the choice of medications alleviated only limited symptoms of end-of-life discomfort.

The pain scales of the population have been extracted from the subset of clinical data called the nursing flow sheet pain management documentation. As explained in Chapter $4,82 \%$ of the deceased patients had one of the four pain scales documentation. 
Most of the cases (70\%) were assessed by the Critical Care Pain Observation Tool (CPOT). The tool was previously validated in a quantitative study by Gelinas et al (2006). Using a repeated measure design method, the study found the CPOT to be an acceptable pain scale tool for cardiac surgery patients in the ICU. It was found that the CPOT scale is a reliable tool that is independent of the patients' consciousness.

According to demographic data from Chapter 4 (Tables 1), the population is slightly female dominated. However, it is safe to conclude that the population is neutral with respect to gender. This result is in line with the latest national statistics in which female mortality is slightly higher than that of males. From Table 2, the patient's age is distributed with a low standard error $(13 / 74=17.5 \%)$, which means that the sample size is sufficient with respect to age. The average age of this sample population closely correlates to the national average life expectancy of 78.8 reported by the Centers for Disease Control and Prevention (Xu et al., 2016).

An enhanced standard of practice and a seamless documentation are suggested to improve the quality of end-of-life care. At the moment, the hospital has just started a new protocol to address end-of-life care issues. It would be helpful to compare this study's results with future data to verify the effect of the new protocol.

\section{Limitation of the Study}

In regard to ethnicity, the distribution of data is abnormal with $85 \%$ of the patients being Caucasian. It reflects the fact that the residents of the geographical area surrounding the hospital mostly incur Caucasian ethnicity. With the scarcity of nonCaucasian samples, it is not feasible to verify any evidence of racial/ethnic disparities for end of life care. As a result, people from racial and ethnic minority groups have not been 
adequately represented in this study. Additional research is needed using minority-rich data. Other limitations of the study are the small sample size of 60 patients and data collection from only one ICU. 


\section{References}

Abrahm, J. L. (2011). Advances in Palliative Medicine and End-of-Life Care. Annual Review of Medicine, 62(1), 187-199.

Bailey, F.A., et al. (2012). Opioid Pain Medication Orders and Administration in the Last Days of Life, Journal of Pain and Symptom Management, 44(5), 681-691.

Beckstrand, R.L., Lamoreaux, N., Luthy, K.E., and Macintosh, J.L.B. (2017). Critical care nurses' perceptions of end of life care obstacles: comparative 17-year data, Dimensions of Critical Care nursing, 36 (2), 94-105.

Brock, G.N., Barnes, C., Ramirez, J.A., and Myers, J. (2011). How to handle mortality when investigating length of hospital stay and time to clinical stability. BMC Medical Research Methodology, 11(144), 1-14.

Cochinov, H.M. (2006). Dying, dignity, and new horizons in palliative end-of-life care. CA: A Cancer Journal for Clinician, 56(2), 84-103

Coombs, M.A., Parker, R., and de Varies, K. (2016). Managing risk during care transitions when approaching end of life: A qualitative study of patients' and health care professionals' decision making, Palliative Medicine, 1-8. DOI: 10.1177/0269216316673476.

Costello, J. (2006). Dying well: Nurses' experiences of "good and bad" deaths in hospital, Journal of Advanced Nursing, 54 (5), 594-601.

Curtis, J.R., Engelberg, R.A., Bensink, M.E., and Ramsey, S.D. (2012). End-of-life care in the intensive care unit: Can we simultaneously increase quality and reduce costs? American Journal of Respiratory and Critical Care Medicine, 186(7), 587-592. 
Efstathiou, N., and Clifford, C. (2011). The critical care nurses' role in end-of-life care: issues and challenges, Nursing in Critical Care, 16(3), 116-123

Fridth, I. (2014). Caring for the dying patient in the ICU - The past, the present and the future, Intensive and Critical Care Nursing, 30(6), 306-311.

Hall, M.J., Levant S., and DeFrances, C.J. (2010). Trends in Inpatient Hospital Deaths: National Hospital Discharge Survey, 2000-2010. NCHS Data Brief, No. 118. Obtained on 4/15/2017 from: www.cdc.gov/nchs/products/databriefs/db118.htm.

Hickman, S. E., Nelson, C. A., Moss, A. H., Hammes, B. J., Terwilliger, A.,... Tolle, S. W. (2009). Use of the Physician Orders for Life-Sustaining Treatment (POLST) Paradigm Program in the Hospice Setting. Journal of palliative medicine, 12(2), $133-141$.

Hov, R. (2007). Nursing care for patients on the edge of life. Ph.D. thesis, Karlstad University, Karlstad, Sweden.

Jukic, M., Saric, L., Prkic, I., and Puljak, L. (2016). Medical futility treatment in intensive care units, Acta Medica Academica, 45(2), 135-144.

Kisvetrova, H., Skoloudik, D., Jonovic, E., Konecna, J., and Miksova, Z. (2016). Dying care interventions in the intensive care unit, Journal of Nursing Scholarship, 48(2), $139-146$.

Mularski, R.A., et al. (2009). Pain management within the palliative and end-of-life care experience in the ICU, CHEST, 135(5), 1360-1369.

Nelson, J.E. (2006). Identifying and overcoming the barriers to high-quality palliative care in the intensive care unit, Critical Care Medicine, 34(11), 324-331. 
Centricity EMR brochure (2017). Document no. DOC0935660 obtained on 4/18/2017 from www.gehealthcare.com.

Critical care statistics, (2017). Society of Critical Care Medicine (SCCM). Retained on 4/15/2017 from: www.sccm.org/Communications/Pages/CriticalCareStats.aspx

Gelinas, C., Fillion, L., Puntillo, K.A., Viens, C. and Fortier, M. (2006). Validation of the critical-care pain observation tool in adult patients. American Journal of critical Care, 15(4), 420-427.

Selanders, L., and Crane, P. (2010). The Voice of Florence Nightingale on Advocacy, The Online Journal of Issues in Nursing, 17(1), DOI: 10.3912/OJIN.

Ternestedt, B.M., Andershed, B., Eriksson, M., and Johansson, I. (2002). A good death: development of a nursing model of care. Journal of Hospice and Palliative Nursing, 4(3), 153-160.

University of Maryland. (2017) Conditions grouped by organ and body system. Obtained on 4/21/2017 from: www.umm.edu/health/medical/altmed/lookup/conditionsgrouped-by-organ-and-body-system

Watson, J. (2008). The philosophy and science of caring. Boulder, CO: University Press of Colorado.

Worster, A., and Haines, T. (2004). Advanced statistics: understanding medical record (MRR) studies, Academic Emergency Medicine, 11(2), 187-192.

Xu, J., Morphy, S.L., Kochanek, K.D., and Bastian, B.A. (2016). Death: final data for 2013. National Vital Statistics Reports, vol.64(2), 1-118. 